\title{
Concomitant valve procedures in patients undergoing continuous-flow left ventricular assist device implantation: A single-center experience
}

Tadahisa Sugiura, MD, PhD, ${ }^{\mathrm{a}, \mathrm{b}}$ Chitaru Kurihara, MD, ${ }^{\mathrm{a}, \mathrm{b}, \mathrm{c}}$ Masashi Kawabori, MD, ${ }^{\mathrm{a}, \mathrm{b}}$

Andre C. Critsinelis, BS, ${ }^{\mathrm{a}, \mathrm{b}}$ Suwei Wang, PhD, ${ }^{\mathrm{d}}$ Andrew B. Civitello, MD, ${ }^{\mathrm{a}, \mathrm{b}}$ Todd K. Rosengart, MD,

O. H. Frazier, MD, ${ }^{a, b}$ and Jeffrey A. Morgan, $M^{a}$

\section{ABSTRACT}

Objective: Long-term support with continuous-flow left ventricular assist devices (CF-LVADs) has improved the outcomes of patients with end-stage heart failure. However, valve disease management in patients who undergo CF-LVAD implantation remains controversial. The aim of this study was to assess our single-center experience with patients who underwent a concomitant valve procedure during implantation of a CF-LVAD.

Methods: From November 2003 through March 2016, 526 patients underwent primary CF-LVAD implantation with a HeartMate II (St Jude Inc, St Paul, Minn; $n=403$ ) or HeartWare (Medtronic, Minneapolis, Minn; $n=123$ ) device at our center. Of those, 91 underwent a concomitant valve procedure during implantation (CF-LVAD+valve procedure group), whereas 435 did not (CFLVAD-only group). We compared preoperative characteristics and short-term and mid-term survival rates between these groups.

Results: The concomitant valve procedures performed included 13 tricuspid valve repairs, 19 aortic valve repairs or replacements, 30 mitral valve repairs or replacements, and 29 double valve repairs or replacements. Survival rates at 1 month, 6 months, 12 months, and 24 months were $90.3 \%, 81.4 \%, 74.9 \%$, and $67.4 \%$, respectively, for the CF-LVAD-only group and $89.0 \%, 75.8 \%$, $70.3 \%$, and $65.9 \%$, respectively, for the CF-LVAD+valve procedure group $(P=.55)$. The results of Cox regression multivariable modeling showed that performing a concomitant valve procedure was not an independent predictor of mortality (hazard ratio, 1.29; 95\% confidence interval, $0.96-1.74 ; P=.08$ ).

Conclusions: In our experience, performing a concomitant valve procedure during CF-LVAD implantation was not associated with an increased mortality rate. The decision to perform a concomitant valve procedure should be made primarily on the basis of clinical indications for the procedure. (J Thorac Cardiovasc Surg 2019;158:1083-9)

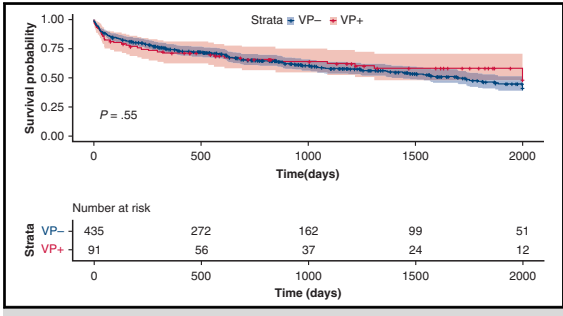

Kaplan-Meier curves of patients who underwent CFLVAD implantation with or without a VP.

\section{Central Message}

Performing a concomitant VP during CFLVAD implantation was not associated with an increased mortality rate. The decision to perform a concomitant VP should be made on the basis of clinical indications.

\section{Perspective}

Valve disease management in patients undergoing CF-LVAD implantation remains controversial. We retrospectively reviewed 526 patients who underwent CF-LVAD implantation at our center with or without a concomitant VP and compared survival between these two patient groups. Performing a concomitant VP during CF-LVAD implantation was not associated with an increased mortality rate.

See Commentaries on pages 1090 and 1092.

\footnotetext{
From the ${ }^{\mathrm{a}}$ Division of Cardiothoracic Transplant and Assist Devices, Baylor College of Medicine, Houston, Tex; ${ }^{\mathrm{b}}$ Department of Cardiopulmonary Transplantation and the Center for Cardiac Support, ${ }^{\mathrm{d}}$ Department of Biostatistics and Epidemiology, Texas Heart Institute, Houston, Tex; and ${ }^{\mathrm{c}}$ Department of Cardiothoracic Surgery, Tokyo Metropolitan Geriatric Hospital and Institute of Gerontology, Tokyo, Japan. Received for publication May 25, 2017; revisions received Jan 25, 2019; accepted for publication Feb 9, 2019; available ahead of print March 20, 2019.

Address for reprints: Chitaru Kurihara, MD, Texas Heart Institute, 6770 Bertner Ave, Houston, TX 77030 (E-mail: chitaru1207@ gmail.com).

$0022-5223 / \$ 36.00$

Copyright (C) 2019 by The American Association for Thoracic Surgery

https://doi.org/10.1016/j.jtcvs.2019.02.040
}

Outcomes for patients with end-stage heart failure who are supported with continuous-flow (CF) left ventricular assist devices (LVADs) have improved. ${ }^{1,2}$ Short-term and midterm survival rates in these patients have increased, and

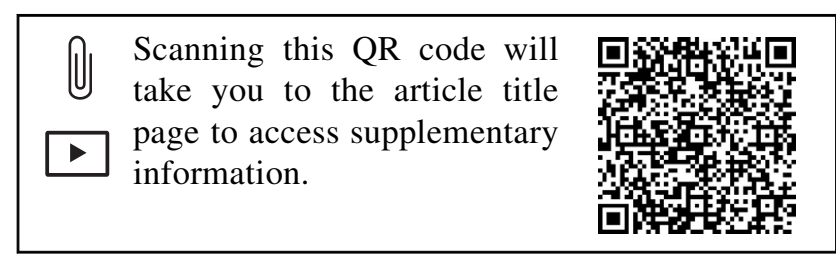




$\begin{array}{ll}\text { Abbreviations and Acronyms } \\ \text { AR } & =\text { aortic valve regurgitation } \\ \text { AVR } & =\text { aortic valve repair or replacement } \\ \text { CF-LVAD }= & \text { continuous-flow left ventricular assist } \\ & \text { device } \\ \text { CPB } & =\text { cardiopulmonary bypass } \\ \text { LVAD } & =\text { left ventricular assist device } \\ \text { LVEDD } & =\text { left ventricular end-diastolic diameter } \\ \text { MR } & =\text { mitral valve regurgitation } \\ \text { MVR } & =\text { mitral valve repair or replacement } \\ \text { RV } & =\text { right ventricle } \\ \text { RVAD } & =\text { right ventricular assist device } \\ \text { TVR } & =\text { tricuspid valve repair or replacement } \\ \text { VP } & =\text { valve procedure }\end{array}$

quality of life has improved. In general, concomitant cardiac procedures increase the complexity of CF-LVAD implantation. Although the indications for performing concomitant cardiac procedures during CF-LVAD implantation are unclear, significant residual valve disease might affect outcomes. ${ }^{3}$

We conducted a retrospective study of patients who underwent the implantation of a CF-LVAD with or without concomitant valve procedures (VPs) at our center. We assessed the short-term and mid-term survival of patients who underwent CF-LVAD implantation with or without a concomitant VP, and we sought to determine whether performing a concomitant VP during CF-LVAD implantation correlates with patient survival. We hypothesized that a tricuspid valve repair or replacement (TVR) as a concomitant VP was not associated with a higher mortality, but a mitral valve repair or replacement (MVR) and/or aortic valve repair or replacement (AVR) might increase perioperative mortality.

\section{METHODS \\ Study Design}

We performed a retrospective review of all patients who underwent primary implantation of a HeartMate II LVAD (St Jude Inc, St Paul, Minn) or HeartWare ventricular assist device (Medtronic, Minneapolis, Minn) with or without a concomitant VP between November 2003 and March 2016 at our center. Patient data, including demographic and preoperative characteristics, and outcomes were collected from the Texas Heart Institute/Baylor College of Medicine clinical database. This study was approved by our institutional review board. Because this study was retrospective, the institutional review board waived the requirement to obtain patient consent. The procedures recorded as concomitant VPs included TVR, AVR, MVR, and double valve repair or replacement. We performed a concomitant VP in patients with moderate and severe aortic valve regurgitation (AR), severe mitral valve regurgitation (MR), and severe tricuspid valve regurgitation.

The operative cannulation strategy for a TVR involved performing bicaval cannulation with inflow occlusion of the right atrium by using snares

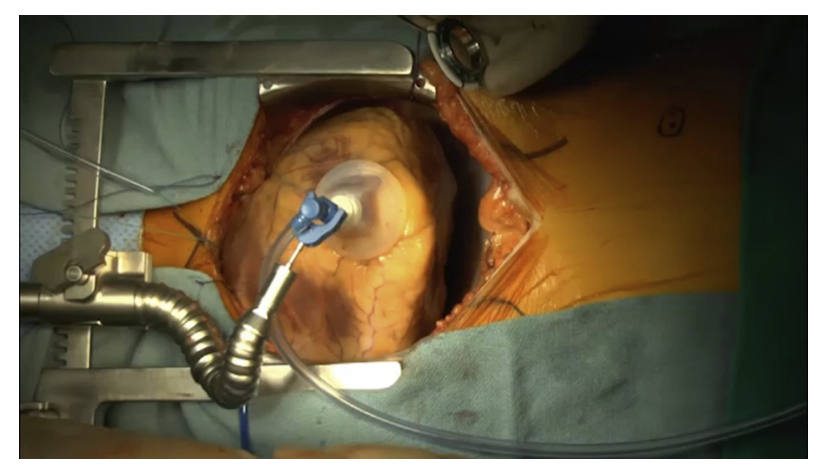

VIDEO 1. Operative video of CF-LVAD HeartWare implantation. Video available at: https://www.jtcvs.org/article/S0022-5223(19)30474-X/fulltext.

followed by a right atriotomy on a beating heart. For an MVR, venous cannulation was also bicaval. For an AVR, cannulation of the aorta and right atrium was performed, as well as cross-clamping of the aorta and retrograde administration of cardioplegia followed by direct coronary ostial administration of cardioplegia after the aortotomy.

\section{Patient Data}

Patient demographic and preoperative characteristics included sex, body surface area, body mass index, cause of heart failure, previous sternotomy, preoperative inotrope use, preoperative laboratory values (white blood cell and platelet counts; international normalized ratio; and serum levels of hemoglobin, sodium, creatinine, blood urea nitrogen, liver enzymes, and albumin), and associated comorbidities, including hypertension, diabetes mellitus, smoking history, and chronic obstructive pulmonary disease. Preoperative hemodynamic and echocardiographic data included central venous pressure, pulmonary artery pressure, pulmonary capillary wedge pressure, left ventricular ejection fraction, cardiac index, left ventricular end-diastolic diameter (LVEDD), AR, MR, and tricuspid valve regurgitation. Operative characteristics included the type of device (HeartMate II [St Jude Inc] or HeartWare [Medtronic]), cardiopulmonary bypass (CPB) time, cross-clamp time, and the need for right ventricular assist device (RVAD) support after surgery. The 30-day outcomes included renal dysfunction, right ventricle (RV) failure, RVAD use, stroke, and 30-day mortality. The outcome variables were survival at 1 month, 6 months, 12 months, and 24 months after CF-LVAD implantation.

\section{Statistical Analysis}

Statistical analysis was performed with SAS 9.2 software (SAS Institute Inc, Cary, NC). Patient demographic and preoperative characteristics, operative characteristics, and outcomes were compared between groups using univariate analyses. Continuous variables are reported as the

TABLE 1. Type and number of concomitant VPs performed

\begin{tabular}{ll}
\hline Type of VP & $\begin{array}{r}\text { Number of each VP performed } \\
(\mathbf{n}=\mathbf{9 1 )}\end{array}$ \\
\hline TVR & $13(14.3)$ \\
AVR & $19(20.9)$ \\
MVR & $30(33.0)$ \\
DVR & $29(31.9)$ \\
\hline
\end{tabular}

Categorical data are shown as the number and percentage (\%) of patients. $V P$, Valve procedure; TVR, tricuspid valve repair or replacement; $A V R$, aortic valve repair or replacement; $M V R$, mitral valve repair or replacement; $D V R$, double valve repair or replacement. 
TABLE 2. Characteristics of CF-LVAD patients

\begin{tabular}{|c|c|c|c|c|}
\hline Variable & Overall $(N=526)$ & CF-LVAD only $(n=435)$ & CF-LVAD and VP $(n=91)$ & $P$ value \\
\hline Age, years & $54.7 \pm 13.5$ & $54.7 \pm 13.7$ & $55.2 \pm 12.8$ & .74 \\
\hline Female sex & $115(21.9)$ & $71(16.3)$ & $44(48.4)$ & $<.001$ \\
\hline BMI & $28.4 \pm 2.7$ & $28.5 \pm 10.6$ & $28.5 \pm 7.1$ & .99 \\
\hline $\mathrm{BSA}, \mathrm{m}^{2}$ & $2.0 \pm 0.2$ & $2.0 \pm 0.3$ & $2.0 \pm 0.2$ & .51 \\
\hline Ischemic cardiomyopathy & $239(45.4)$ & $199(45.7)$ & $40(44.0)$ & .76 \\
\hline Hypertension & $320(60.8)$ & $268(61.6)$ & $52(57.1)$ & .43 \\
\hline Diabetes mellitus & $232(44.1)$ & $199(45.7)$ & $33(36.3)$ & .10 \\
\hline Smoking history & $219(41.6)$ & $178(40.9)$ & $41(45.1)$ & .47 \\
\hline Chronic obstructive pulmonary disease & $74(14.1)$ & $64(14.7)$ & $10(11.0)$ & .35 \\
\hline Previous cardiac surgery & $179(34.0)$ & $146(33.6)$ & $33(36.3)$ & .62 \\
\hline Preoperative inotrope use & $444(84.4)$ & $368(84.6)$ & $76(83.5)$ & .80 \\
\hline Bridge to transplantation & $283(53.8)$ & $233(53.6)$ & $50(54.9)$ & .81 \\
\hline \multicolumn{5}{|l|}{ INTERMACS profile } \\
\hline Profile 1 & $75(14.3)$ & $61(14.0)$ & $14(15.4)$ & .74 \\
\hline Profile 2 & $173(32.9)$ & $142(32.6)$ & $31(34.1)$ & .51 \\
\hline Profile 3 & $200(38.0)$ & $166(38.2)$ & $34(37.4)$ & .89 \\
\hline \multicolumn{5}{|l|}{ Laboratory values } \\
\hline Hemoglobin, g/dL & $11.5 \pm 2.1$ & $11.6 \pm 2.2$ & $11.4 \pm 1.9$ & .42 \\
\hline WBCs, $1000 / \mathrm{mm}^{3}$ & $9.3 \pm 4.6$ & $9.4 \pm 4.7$ & $8.8 \pm 4.4$ & .30 \\
\hline Platelets, $1000 / \mathrm{mm}^{3}$ & $206.6 \pm 93.5$ & $207.2 \pm 94.7$ & $204.2 \pm 87.6$ & .78 \\
\hline Sodium, mEq/L & $135.1 \pm 4.5$ & $135.2 \pm 4.5$ & $134.9 \pm 4.6$ & .60 \\
\hline Creatinine, $\mathrm{mg} / \mathrm{dL}$ & $1.4 \pm 0.7$ & $1.4 \pm 0.7$ & $1.5 \pm 0.9$ & .18 \\
\hline BUN, mg/dL & $31.1 \pm 18.5$ & $31.1 \pm 18.8$ & $31.4 \pm 16.8$ & .89 \\
\hline AST, U/L & $72.4 \pm 154.5$ & $64.5 \pm 100.5$ & $110.2 \pm 296.3$ & .01 \\
\hline ALT, U/L & $81.1 \pm 180.2$ & $74.2 \pm 160.1$ & $114.4 \pm 252.4$ & .05 \\
\hline Total bilirubin, $\mathrm{mg} / \mathrm{dL}$ & $1.6 \pm 2.5$ & $1.7 \pm 2.7$ & $1.8 \pm 2.1$ & .70 \\
\hline Albumin, $\mathrm{g} / \mathrm{dL}$ & $3.5 \pm 0.6$ & $3.6 \pm 0.6$ & $3.5 \pm 0.7$ & .42 \\
\hline INR & $1.2 \pm 0.4$ & $1.3 \pm 0.4$ & $1.4 \pm 0.5$ & .09 \\
\hline \multicolumn{5}{|l|}{ Echocardiogram } \\
\hline LVEF, \% & $21.7 \pm 3.6$ & $21.8 \pm 3.8$ & $21.5 \pm 2.8$ & .45 \\
\hline LVEDD, cm & $6.5 \pm 1.0$ & $6.5 \pm 1.0$ & $6.8 \pm 1.2$ & .02 \\
\hline Severe TR & $59(11.2)$ & $43(9.9)$ & $16(17.6)$ & .03 \\
\hline Severe MR & $108(20.5)$ & $76(17.5)$ & $32(35.2)$ & $<.001$ \\
\hline Severe AR & $6(1.1)$ & $1(0.2)$ & $5(5.5)$ & $<.001$ \\
\hline \multicolumn{5}{|l|}{ Right heart catheterization } \\
\hline $\mathrm{CI}, \mathrm{L} / \mathrm{min} / \mathrm{m}^{2}$ & $1.8 \pm 0.5$ & $1.9 \pm 0.6$ & $1.8 \pm 0.5$ & .52 \\
\hline Central venous pressure, $\mathrm{mm} \mathrm{Hg}$ & $11.7 \pm 7.4$ & $11.5 \pm 7.2$ & $12.5 \pm 8.6$ & .32 \\
\hline PAP, $\mathrm{mm} \mathrm{Hg}$ & $35.0 \pm 11.0$ & $35.4 \pm 10.7$ & $36.9 \pm 12.3$ & .28 \\
\hline PCWP, $\mathrm{mm} \mathrm{Hg}$ & $24.7 \pm 10.1$ & $24.5 \pm 10.2$ & $26.2 \pm 10.1$ & .22 \\
\hline
\end{tabular}

Continuous data are shown as the mean \pm standard deviation. Categorical data are shown as the number and percentage of patients. $C F$-LVAD, Continuous-flow left ventricular assist device; $V P$, valve procedure; $B M I$, body mass index; $B S A$, body surface area; INTERMACS, Interagency Registry of Mechanically Assisted Circulatory Support; WBC, white blood cell; $B U N$, blood urea nitrogen; $A S T$, aspartate aminotransferase; $A L T$, alanine aminotransferase; $I N R$, international normalized ratio; $L V E F$, left ventricular ejection fraction; $L V E D D$, left ventricular end-diastolic diameter; $T R$, tricuspid valve regurgitation; $M R$, mitral valve regurgitation; $A R$, aortic valve regurgitation; $C I$, cardiac index; $P A P$, pulmonary artery pressure; $P C W P$, pulmonary capillary wedge pressure.

mean \pm standard deviation; these variables were compared between groups by using analysis of variance. Categorical variables are reported as the number and percentage and were compared between groups by using the Fisher exact test. Kaplan-Meier analysis and the log rank test were performed to compare overall survival between the groups; patients were not censored for heart transplantation or LVAD exchange. Cox proportional hazard regression was used to derive the hazard ratios and $95 \%$ confidence intervals. Cox regression multivariable modeling was used to test whether performing a concomitant VP during the implantation of a CF-LVAD was a significant predictor of overall postoperative mortality. For our Cox proportional hazards analysis, all preoperative variables were examined by using univariate Cox proportional hazards analysis. Variables with $P<.20$ were included in our final multivariate model, and concomitant VP was forced into our model. Variables with a variance inflation rate $>10$ were excluded 
TABLE 3. Operative variables in the CF-LVAD-only group and CF-LVAD with VP group

\begin{tabular}{lcccc}
\hline \multicolumn{1}{c}{ Variable } & Overall $(\mathbf{N}=\mathbf{5 2 6})$ & CF-LVAD only $(\mathbf{n}=\mathbf{4 3 5})$ & CF-LVAD with VP $(\mathbf{n}=\mathbf{9 1})$ & $\boldsymbol{P}$ value \\
\hline CPB use & $502(95.6)$ & $413(94.9)$ & $91(100)$ & .86 \\
CPB time, min & $85.4 \pm 53.6$ & $78.3 \pm 49.5$ & $120.1 \pm 58.9$ & $36(39.6)$ \\
Cross-clamp use & $57(10.8)$ & $21(4.8)$ & $52.2 \pm 38.4$ & $<.001$ \\
Cross-clamp time, min & $50.9 \pm 41.2$ & $49.3 \pm 45.3$ & $306.6 \pm 129.4$ & .001 \\
Operative time, min & $266.1 \pm 99.7$ & $266.4 \pm 99.9$ & $8(8.8)$ & .75 \\
Need for an RVAD & $42(8.0)$ & $34(7.8)$ & $<.001$ \\
\hline
\end{tabular}

Continuous data are shown as the mean \pm standard deviation. Categorical data are shown as the number and percentage of patients. CF-LVAD, Continuous-flow left ventricular assist device; $V P$, valve procedure; $C P B$, cardiopulmonary bypass; $R V A D$, right ventricular assist device.

from our final model for introducing multicollinearity. The implantation of a HeartWare [Medtronic] CF-LVAD is shown in Video 1.

\section{RESULTS}

\section{Characteristics of CF-LVAD Recipients}

During the study period, 526 patients (115 women; mean age, $54.7 \pm 13.5$ years) with chronic heart failure underwent implantation of a CF-LVAD (403 HeartMate II [St Jude Inc], 123 HeartWare [Medtronic]) at our center. The mean follow-up was 669 days (median, 520 days). Of the 526 patients, 91 underwent a concomitant VP. The type and number of concomitant VPs performed are shown in Table 1. Of the patients with double valve repair or replacement, $25 \mathrm{had}$ MVR with TVR, 3 had AVR with MVR, and 1 had AVR with TVR. Patient demographic and preoperative characteristics for these subgroups are summarized in Table 2. The percentage of women in the CF-LVAD+VP group was greater than that in the CF-LVAD-only group $(16.3 \%$ vs $48.4 \% ; P<.001)$. Regarding echocardiographic data, the mean LVEDD was greater in the CF-LVAD+VP group $(6.8 \pm 1.2 \mathrm{~cm}$ vs $6.5 \pm 1.0 \mathrm{~cm} ; P=.02)$.

\section{CPB Time and Cross-Clamp Use}

As expected, mean CPB time and mean operative time were longer in the CF-LVAD+VP group than in the CFLVAD-only group (CPB time, $120.1 \pm 58.9$ vs
$78.3 \pm 49.5$ minutes; $P<.001 ;$ operative time, $306.6 \pm 129.4$ vs $266.4 \pm 99.9$ minutes; $P<.001)$. Crossclamp use was more frequent in the CF-LVAD+VP group than in the CF-LVAD-only group (36 [39.6\%] vs 21 [4.8\%]; $P<.001$; Table 3). Operative data for each type of CF-LVAD+VP group are shown in Table 4.

\section{Thirty-Day Outcomes and Length of Stay}

Table 5 shows a comparison of 30-day outcomes and length of stay between patients with and without a concomitant VP. RV failure and stroke were significantly increased in the CF-LVAD+VP group, but there was no difference in other early adverse events including renal dysfunction, RVAD use, or 30-day mortality. There was no significant difference in length of hospital stay between the groups.

\section{Survival After CF-LVAD Implantation With or Without a Concomitant VP}

Survival rates at $1,6,12$, and 24 months were $90.3 \%$, $81.4 \%, 74.9 \%$, and $67.4 \%$, respectively, for the CFLVAD-only group and $89.0 \%, 75.8 \%, 70.3 \%$, and $65.9 \%$, respectively, for the CF-LVAD+VP group $(P=.55$; Table 6 , Figure 1$)$. In the CF-LVAD-only group, 81 patients $(18.6 \%)$ underwent heart transplantations, whereas 18 patients $(19.8 \%)$ underwent heart transplantations in the CF-LVAD+VP group $(P=.8)$. In the CF-

TABLE 4. Operative data for each type of CF-LVAD with VP group

\begin{tabular}{lcccc}
\hline \multicolumn{1}{c}{ Variable } & $\begin{array}{c}\text { CF-LVAD with TVR } \\
(\mathbf{n}=\mathbf{1 3})\end{array}$ & $\begin{array}{c}\text { CF-LVAD with AVR } \\
(\mathbf{n}=\mathbf{1 9})\end{array}$ & $\begin{array}{c}\text { CF-LVAD with MVR } \\
(\mathbf{n}=\mathbf{3 0})\end{array}$ & $\begin{array}{c}\text { CF-LVAD with DVR } \\
(\mathbf{n}=\mathbf{2 9})\end{array}$ \\
\hline CPB use & $13(100.0)$ & $19(100.0)$ & $30(100.0)$ & $29(100.0)$ \\
CPB time, min & $121.2 \pm 25.7$ & $141.1 \pm 76.4$ & $91.2 \pm 35.8$ & $137.9 \pm 60.3$ \\
Cross-clamp use & 0 & $19(100.0)$ & $3(10.0)$ & $14(48.3)$ \\
Cross-clamp time, min & 0 & $59.3 \pm 45.8$ & $52.3 \pm 14.4$ & $41.6 \pm 40.2$ \\
Operative time, min & $295.7 \pm 220.0$ & $343.9 \pm 122.2$ & $273.1 \pm 70.9$ & $321.8 \pm 176.9$ \\
Need for an RVAD & $2(15.4)$ & $2(10.5)$ & $1(3.3)$ & $3(10.3)$ \\
\hline
\end{tabular}

Continuous data are shown as the mean \pm standard deviation. Categorical data are shown as the number and percentage of patients. $C F-L V A D$, Continuous-flow left ventricular assist device; TVR, tricuspid valve repair or replacement; $A V R$, aortic valve repair or replacement; $M V R$, mitral valve repair or replacement; $D V R$, double valve repair or replacement; $C P B$, cardiopulmonary bypass; $R V A D$, right ventricular assist device. 
TABLE 5. Thirty-day outcomes and length of hospital stay

\begin{tabular}{lccc}
\hline \multicolumn{1}{c}{ Variable } & $\begin{array}{c}\text { CF-LVAD only } \\
(\mathbf{n}=\mathbf{4 3 5})\end{array}$ & $\begin{array}{c}\text { CF-LVAD with } \\
\text { VP }(\mathbf{n}=\mathbf{9 1})\end{array}$ & $\boldsymbol{P}$ value \\
\hline Thirty-day outcome & & & \\
Renal dysfunction & $64(14.7)$ & $11(12.1)$ & .51 \\
Right ventricle failure & $63(14.5)$ & $26(28.6)$ & .001 \\
RVAD & $32(7.4)$ & $6(6.6)$ & .8 \\
Stroke & $15(3.4)$ & $14(15.4)$ & $<.001$ \\
30-Day mortality & $42(9.7)$ & $9(9.9)$ & .95 \\
Length of hospital stay & $40.9 \pm 34.9$ & $47.5 \pm 44.2$ & .06 \\
\hline Continuous data are shown as the mean \pm standard deviation. Categorical data are \\
shown as the number and percentage of patients. $C F-L V A D$, Continuous-flow left ven- \\
tricular assist device; $V P$, valve procedure; $R V A D$, right ventricular assist device.
\end{tabular}

LVAD-only group, 73 patients $(16.8 \%)$ underwent LVAD exchange, whereas 20 patients $(22.0 \%)$ underwent LVAD exchange in the CF-LVAD+VP group $(P=.24)$. No significant differences were observed in overall survival rates between the CF-LVAD-only group and each type of CFLVAD + VP group, except that the survival rate in the CFLVAD + MVR group was greater than the survival rate in the CF-LVAD-only group $(P=.02)$. Using Cox regression multivariable modeling, we found that performing a VP during the implantation of a CF-LVAD was not an independent predictor of mortality in these patients (hazard ratio, 1.29; 95\% confidence interval, 0.96-1.74; $P=.08$; Table E1).

\section{DISCUSSION}

In this study, we assessed whether performing a VP during CF-LVAD implantation correlates with short-term and mid-term patient survival rates. Our results show that performing a VP during CF-LVAD implantation did not affect short-term or mid-term patient survival rates, despite the finding that VPs increased short-term RV failure and CPB and operative times and necessitated aortic crossclamping with cardioplegic arrest.

When we compared the overall survival rates between the CF-LVAD-only group and each type of CF-LVAD+VP group, we found similar results, except for the CFLVAD+MVR group, which had a better overall survival rate than the CF-LVAD-only group. In general, MR does not require repair during CF-LVAD implantation. ${ }^{4}$ In endstage heart failure, MR is due to annular enlargement. When the left ventricle is decompressed by the implantation of a CF-LVAD, the LVEDD and severity of MR might be significantly reduced. ${ }^{5}$ Tanaka and colleagues ${ }^{6}$ reported that LVAD patients with surgically corrected MR had improved midterm hemodynamics and survival rates when compared with patients who had spontaneously resolved MR. They speculated that the improvement in pulmonary vascular resistance might have positively enhanced the midterm outcomes. In addition, Fukuhara and colleagues ${ }^{7}$ reported that concurrent mitral repair with $\mathrm{CF}$ LVAD implantation is a protective factor for late occurrence of right heart failure. Therefore, the higher overall survival rate that we observed in the CF-LVAD+MVR group versus the CF-LVAD-only group suggests that performing concomitant MVR with CF-LVAD implantation might be more beneficial for patients with severe MR.

In our study, short-term RV failure was increased in the CF-LVAD+VP group. This increase might be due to prolonged CPB time and the necessity of aortic crossclamping with cardioplegic arrest. John and colleagues ${ }^{8}$ reported similar results in that patients who underwent HeartMate II (St Jude Inc) placement with a concurrent VP had more RV dysfunction, as well as higher early mortality rates, than did those who underwent only HeartMate II implantation. In addition, the stroke rate in the CFLVAD+VP group was fivefold higher than that in the CFLVAD-only group; this might also be attributable to the significantly longer CPB time and higher cross-clamp use in patients who underwent a concomitant VP.

The indications for performing a concomitant VP in patients undergoing CF-LVAD implantation remain controversial. In the Heartmate II (St Jude Inc) bridge to transplant trial, Pal and colleagues ${ }^{9}$ showed that performing concurrent cardiac surgical procedures significantly increased the risk of mortality associated with HeartMate II implantation. The 30-day mortality rate for patients who underwent HeartMate II (St Jude Inc) implantation

TABLE 6. Survival of CF-LVAD-only and CF-LVAD with VP groups

\begin{tabular}{|c|c|c|c|c|c|}
\hline \multirow[b]{2}{*}{ Type of procedure } & \multicolumn{4}{|c|}{ Survival (postoperative month) } & \multirow[b]{2}{*}{ Overall $P$ value } \\
\hline & $\mathbf{1}$ & 6 & 12 & 24 & \\
\hline CF-LVAD only, $\%$ & 90.3 & 81.4 & 74.9 & 67.4 & \\
\hline CF-LVAD with VP, $\%$ & 89.0 & 75.8 & 70.3 & 65.9 & .55 \\
\hline \multicolumn{6}{|l|}{ VP groups, \% } \\
\hline TVR & 100 & 84.6 & 76.9 & 69.2 & .86 \\
\hline AVR & 84.2 & 84.2 & 78.9 & 73.7 & .94 \\
\hline MVR & 96.7 & 86.7 & 83.3 & 83.3 & .02 \\
\hline DVR & 82.8 & 58.6 & 51.7 & 48.3 & .10 \\
\hline
\end{tabular}

$C F-L V A D$, Continuous-flow left ventricular assist device; $V P$, valve procedure; $T V R$, tricuspid valve repair or replacement; $A V R$, aortic valve repair or replacement; $M V R$, mitral valve repair or replacement; $D V R$, double valve repair or replacement. 


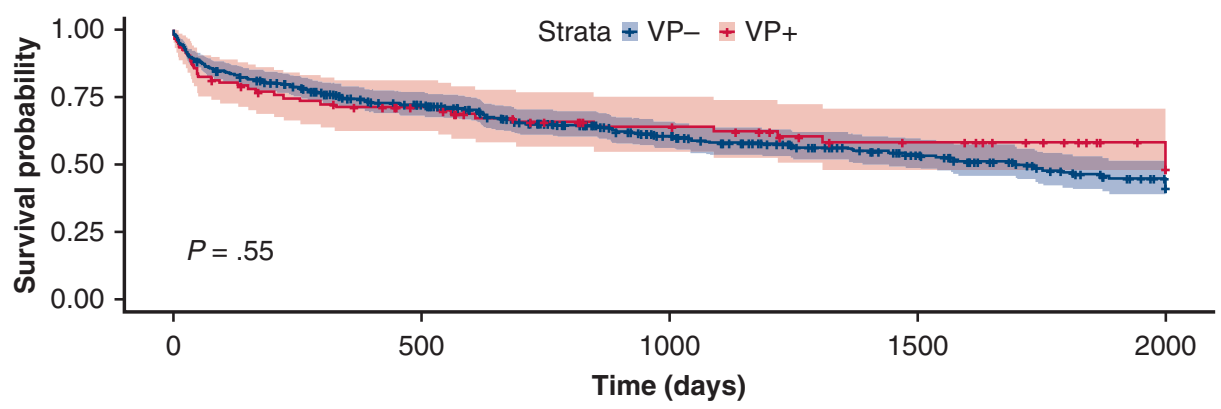

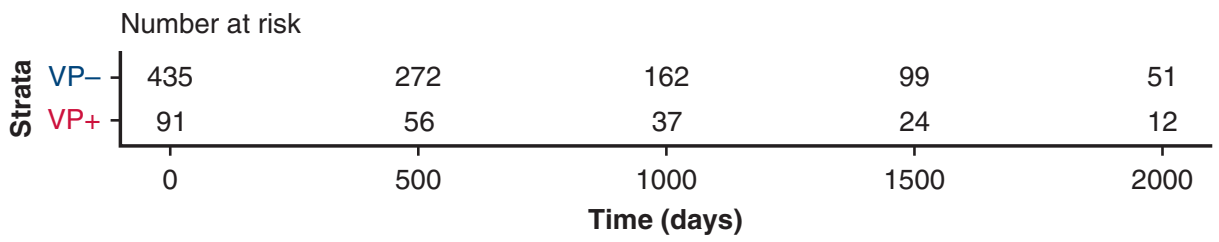

FIGURE 1. Kaplan-Meier survival curves of patients who underwent continuous-flow left ventricular assist device (CF-LVAD) implantation with (VP+) or without $(V P-)$ a concomitant valve procedure.

with concurrent cardiac procedures was twice that for patients who underwent implantation only $(11.1 \%$ vs $5.9 \%)$; the hazard ratio for concurrent procedures adjusted for baseline parameters was 1.82 . In the same report, the authors reviewed the records of 170 patients who underwent isolated LVAD implantation and 81 patients who underwent LVAD implantation with a concomitant cardiac procedure, and they concluded that concomitant tricuspid valve repair or patent foramen ovale closure did not increase the perioperative mortality rate, whereas concomitant aortic VPs did. ${ }^{9}$

In recent studies, similar outcomes have been reported in CF-LVAD-only patients and patients who underwent CF-LVAD implantation and concomitant procedures. Piacentino and colleagues ${ }^{10}$ reported similar survival rates between patients who underwent CF-LVAD implantation with concomitant tricuspid valve repair and patients who underwent CF-LVAD implantation alone. Furthermore, patients with severe tricuspid valve regurgitation who underwent CF-LVAD implantation with concomitant tricuspid valve repair had fewer hospital readmissions and a lower rate of right heart failure than did those who underwent isolated LVAD implantation. In addition, Morgan and colleagues ${ }^{11}$ reported that concomitant cardiac procedures performed during implantation of a CF-LVAD in 130 patients did not increase the perioperative or mid-term mortality rate, and no additive procedural risk was observed for patients who underwent concomitant AVR. In a study of 398 patients who underwent isolated CF-LVAD implantation and 216 patients who underwent CF-LVAD implantation with various concomitant procedures, the survival rate was comparable between groups and was not influenced by the concomitant procedures. ${ }^{12}$

Regarding our institutional protocol for performing concomitant VPs at LVAD implantation, we typically treat aortic insufficiency that is greater than mild when an LVAD is implanted. Surgical procedures that our group has performed include a central Park stitch, a modified central Park stitch, patch closure of the left ventricular outflow tract, sandwich closure of the valve, and aortic valve replacement with a bioprosthetic valve. The type of procedure used to address AR depends on the quality of the native leaflet of the aortic valve, the function of the RV and its ability to tolerate prolonged cross clamping, and surgeon preference. Our current practice is to perform a concomitant aortic valve replacement using a bioprosthetic valve for AR that is greater than mild. For patients with a mechanical aortic valve, we typically perform a sandwich closure of the valve with a pledgeted mattress suture. For patients in whom the bioprosthetic aortic valve functions well, we do not perform any additional procedure to the aortic valve. For MR, our current practice is to rely on decompression/ unloading of the left ventricle by the LVAD to address the MR rather than performing a concomitant mitral valve repair. For moderate to severe or severe tricuspid regurgitation, our current practice is to perform a concomitant tricuspid valve repair using a $26-\mathrm{mm}$ or $28-\mathrm{mm}$ annuloplasty ring at the time of LVAD implantation. We close all patent foramen ovales in patients undergoing LVAD implantation. Regarding the left atrial appendage, we have recently started ligating the left atrial appendage at the time of LVAD implantation in patients with a history of atrial fibrillation. Additional intrainstitutional analysis is required and is under way to determine if there are clinical advantages associated with particular approaches in these cases and to identify thresholds for addressing concomitant valvular pathology at the time of LVAD implantation.

Our study has several limitations. First, the study was based on a single-center experience from which we initiated 
this research; therefore, the results might not be generalizable to other LVAD programs. Second, our study was not a prospective randomized trial. Finally, we did not evaluate each concomitant VP separately, but instead we grouped them together.

\section{CONCLUSIONS}

Although performing a concomitant VP during CFLVAD implantation prolonged the operative time, performing a concomitant VP was not associated with an increase in mortality rate. Our findings suggest that the decision to perform a concomitant VP should be made on the basis of clinical indications alone and should not be a limitation in patient selection for long-term CF-LVAD therapy.

\section{Conflict of Interest Statement}

Authors have nothing to disclose with regard to commercial support.

The authors thank MacArthur A. Elayda, MD, $\mathrm{PhD}$, of the Department of Biostatistics and Epidemiology at the Texas Heart Institute, for his timely help in analyzing our large data set. The Section of Scientific Publications at Texas Heart Institute provided editorial support.

\section{References}

1. Slaughter MS, Rogers JG, Milano CA, Russell SD, Conte JV, Feldman D, et al. Advanced heart failure treated with continuous-flow left ventricular assist device. N Engl J Med. 2009;361:2241-51.

2. Pagani FD, Miller LW, Russell SD, Aaronson KD, John R, Boyle AJ, et al. Extended mechanical circulatory support with a continuous-flow rotary left ventricular assist device. J Am Coll Cardiol. 2009;54:312-21.
3. Rao V, Slater JP, Edwards NM, Naka Y, Oz MC. Surgical management of valvular disease in patients requiring left ventricular assist device support. Ann Thorac Surg. 2001;71:1448-53.

4. Jaik N, Higgins RS, Whitson BA. Simultaneous procedures during left ventricular assist device implantation: is less always more? Curr Heart Fail Rep. 2014; 11:98-102.

5. Morgan JA, Brewer RJ, Nemeh HW, Murthy R, Williams CT, Lanfear DE, et al. Left ventricular reverse remodeling with a continuous flow left ventricular assist device measured by left ventricular end-diastolic dimensions and severity of mitral regurgitation. ASAIO J. 2012;58:574-7.

6. Tanaka A, Onsager D, Song T, Cozadd D, Kim G, Sarswat N, et al. Surgically corrected mitral regurgitation during left ventricular assist device implantation is associated with low recurrence rate and improved midterm survival. Ann Thorac Surg. 2017;103:725-33.

7. Fukuhara S, Takeda K, Chiuzan C, Han J, Kurlansky PA, Takayama H, et al. Concomitant mitral repair and continuous-flow left ventricular assist devices: is it warranted? J Thorac Cardiovasc Surg. 2017;154:1303-12.e4.

8. John R, Naka Y, Park SJ, Sai-Sudhakar C, Salerno C, Sundareswaran KS, et al. Impact of concurrent surgical valve procedures in patients receiving continuous-flow devices. J Thorac Cardiovasc Surg. 2014;147:581-9; discussion 589.

9. Pal JD, Klodell CT, John R, Pagani FD, Rogers JG, Farrar DJ, et al. Low operative mortality with implantation of a continuous-flow left ventricular assist device and impact of concurrent cardiac procedures. Circulation. 2009;120:S215-9.

10. Piacentino V III, Ganapathi AM, Stafford-Smith M, Hsieh MK, Patel CB Simeone AA, et al. Utility of concomitant tricuspid valve procedures for patients undergoing implantation of a continuous-flow left ventricular device. J Thorac Cardiovasc Surg. 2012;144:1217-21.

11. Morgan JA, Tsiouris A, Nemeh HW, Hodari A, Karam J, Brewer RJ, et al. Impact of concomitant cardiac procedures performed during implantation of long-term left ventricular assist devices. J Heart Lung Transplant. 2013;32: $1255-61$.

12. Maltais S, Haglund NA, Davis ME, Aaronson KD, Pagani FD, Dunlay SM, et al. Outcomes after concomitant procedures with left ventricular assist device implantation: implications by device type and indication. ASAIO J. 2016;62:403-9.

Key Words: left ventricular assist device, heart failure, concomitant valve procedures, valve disease 
TABLE E1. Cox multivariable logistic regression analysis: predictors of postoperative mortality

\begin{tabular}{|c|c|c|c|}
\hline Variable & HR & $P$ value & $95 \% \mathrm{CI}$ \\
\hline Concomitant VP & 1.29 & .08 & $0.96-1.74$ \\
\hline Age, years & 1.02 & $<.01$ & $1.01-1.04$ \\
\hline BMI & 1.06 & .03 & $1.01-1.12$ \\
\hline Previous cardiac surgery & 1.48 & .01 & $1.09-2.00$ \\
\hline Preoperative short-term MCS & 1.12 & .43 & $0.84-1.49$ \\
\hline Preoperative inotropes & 1.78 & $<.01$ & $1.14-2.77$ \\
\hline Device type & 1.35 & .10 & $0.94-1.93$ \\
\hline \multicolumn{4}{|l|}{ Echocardiogram } \\
\hline Severe TR & 1.57 & .03 & $1.03-2.41$ \\
\hline Severe MR & 0.84 & .37 & $0.59-1.21$ \\
\hline Severe AR & 0.97 & .97 & $0.30-3.19$ \\
\hline \multicolumn{4}{|l|}{ Right heart catheterization } \\
\hline Cardiac index, $\mathrm{L} / \mathrm{min} / \mathrm{m}^{2}$ & 1.50 & .10 & $0.92-2.44$ \\
\hline Central venous pressure, $\mathrm{mm} \mathrm{Hg}$ & 1.04 & .06 & $0.99-1.09$ \\
\hline Pulmonary artery pressure, $\mathrm{mm} \mathrm{Hg}$ & 0.99 & .95 & $0.96-1.03$ \\
\hline PCWP, mm Hg & 0.98 & .51 & $0.94-1.03$ \\
\hline
\end{tabular}

